MATEC Web of Conferences 15, 01036 (2014)

DOI: $10.1051 /$ matecconf/ 20141501036

(C) Owned by the authors, published by EDP Sciences, 2014

\title{
Flexibility of Supply Chain in Industrialised Building System (IBS)
}

\author{
U. Kassim ${ }^{1}$, S. Abdullah ${ }^{2}$, Z. Udin ${ }^{3}$ \\ ${ }^{1,3}$ College of Business, Universiti Utara Malaysia (UUM), Sintok, Kedah, 06010, Malaysia \\ ${ }^{2}$ School of Environmental Engineering, Universiti Malaysia Perlis (UniMAP), Kompleks Pusat \\ Pengajian Jejawi 3,Arau, Perlis, 02600, Malaysia
}

\begin{abstract}
It is irrefutable that the construction industry is in need of a highly technological construction method or system for the simple aim of giving it a push it deserves. In Malaysia this technologically enhanced method is known as the Indutrialised Building System (IBS). Concerted efforts have been made for the past decade by various responsible parties especially by the government. Therefore, the IBS 'Road Map' 20032010 was introduced and now continues with the IBS 'road map' 2011-2015. However, its performance is still at its infancy, which target is only at an initial stage. This study seeks to identify and analyse the factor of the IBS' system's supply chain flexibility as a factor on the success of the system itself. It has been a suspicion that there exists a condition and situation where the supply chain is too rigid and is not flexible in fulfilling the needs and demands of the IBS development in Malaysia. This inflexible situation has brought about a broad range of problems and has stood in the way of the development of the industrialised building system, despite it being introduced since 1964, or 49 years ago. Flexibility in the IBS supply chain is very important and is associated with other industries like transportation, manufacturing industry, and others. Up until now, we have yet to discover any special studies related to the flexibility in the IBS supply chain in this country. Responding to this challenge, this research is hoped to be able to provide sufficient feedback to the solution to the IBS supply chain flexibility issue. The researcher is confident that the poor system flow of supply chain has impeded the advancement of the Industrialised Building System that has long been open to debate.
\end{abstract}

\section{Introduction}

The construction industry has given a great contribution to the national economic growth. Nonetheless, in the first quarter of 2012, the work value of the construction sector produced remained at RM17.73 billion, representing an increase of mere 14.2 [1]. This statement implies the need for active effort to stimulate the exponential growth of the construction industry. It is due to this reason that the construction industry necessitates the smooth running of the IBS or a system that is catalytic to the fulfillment of the needs and demands of the national construction industry. However, the IBS 'Road Map' 2003-2010 and the IBS 'Road map' 2011-2015 did not seem to achieve much and were only concentrating on early targets [2]. What are the factors and issues of inflexibility of the IBS' 
supply chain that obstructs the success of the IBS for almost 50 years? Reffering Othman [3] fundamentally is a chain of companies involved in complex activities and in multiple processes, and with such complexity, the management requires a sense of coordination as to improve the performance of the supply chain such as to the information flow, services, finance and materials. According to Nawi et.al [4] the term 'supply chain' is defined as the 'key of integration of a business process from the end-user to through the original supplier who produces the products, services and information where it is an added value to the customers and stakeholders.

\section{Research Method}

This paper is an initial-stage of ongoing $\mathrm{PhD}$ study regarding the flexibility of the IBS' supply chain. Therefore, the information presented in this working paper primarily leans on studies on literature that is relevant to the fields of the IBS and construction. The method of the research lies in identifying that literature studies serve as "a segment of the critical analysis of knowledge' published through summaries, classification, and comparison conducted in the past in research studies, literature review and article theories". A literature review aims at explaining, concluding, evaluating, elaborating or integrating the content of a piece of information. Completing a literature study would be a significant intellectual achievement in its own right, where prior to this, it necessitates a work analysis and synthesis in whichever way possible, in order to gain new understanding and discovery, and it serves as a pioneer for new researches. Through this method, the definition, application, and issues related to the flexibility of the supply chain in the Industrialised Building System of the construction industry should be explored and placed under the limelight.

Simultaneously, various steps and strategies are put forth and discussed towards enhancing the IBS' supply chain flexibility. All the data and information gathered are directly from the books, articles and other printed materials obtained from both local and international journals, also proceedings and bulletins. The established findings are not destined to be conclusive, but they do spark the fuel for debates and become the platform to collect the responses and feedback from those involved in this construction industry. More evidence is needed to offer support for this paper work and further studies need to be done as to validate the method and proposal that have been produced. Writer hopes that the initial paper work will construct a robust platform for future research and also become preparatory stage for more detailed and comprehensive thesis writing.

\section{Overview Issues, Problems And Achievements Of The Malaysian Ibs Construction Industry}

The dented reputation of the readily-installed building system is explained by the fact that initially, the quality control level is still low, also there is the lack of technical experiences, further leading to several noticeable flaws like cracks, moisture leakage, leakage and low degree of thermal insulation [5]. In the meantime, the poor connection and relationships in the IBS systems are also apparent, where these systems are critical and sensitive to flaws and skilled technical work, [6].

The shortage of raw materials, lateness, or delays in supplying and also poor weather have also adversely impacted the transportation in the way that these explain why there is a great delay in the completion of many IBS projects,[7]. Other than that, large cost and capital including setting up factories, supplying machineries and molds, and the whole expenses of traveling (totalling 3\%-5\% of their total cost for distance not more than $50 \mathrm{~km}-100 \mathrm{~km}$. Costs can only be reduced in large-scale projects when employing repetitious method in designs [8]. The low costs of unskilled workers have made the contractors favour the conventional method than the IBS, [9]. Apart from that, the 
transportation process also has its limit such as the difficulties of getting to the site and of transporting large components from the factory to the construction site [8].

This supply chain process also requires a wide store to be provided in a factory to keep IBS components and there is also a need for areas for the trailer and cranes to move about [8].

According to Kamar [11] looking at the overall registered contractors and those who have attended the CDB-organised training, by average and through sampling calculation, only $22 \%$ from these contractors have been offered the IBS project tender offer, while only $9 \%$ of the contractors have implemented the IBS project. This total is too meager if compared to the overall number of registered contractors. The majority of them are involved in the installation work of the castled steel frames namely the kind of work that is common in the construction industry whether the project uses the IBS method or conventional method. The lack of involvement of the contractors demonstrates that training alone is not enough to help the contractors; most of them need the guidance in the form of consultation, via integrated programmed also better incentives from the government.

It is also found that there are no specific rules and regulations provided by the government's authorities over the implementation of the IBS; $[15,16]$ thus, the government should make the move to ensure that the policies are carried out towards implementing the IBS so as to initiate the motivation.

The construction industry's growth is also evolving and is in need of due attention, to drive the development and advancement of the country. This term is in reference of the requirement of the IBS construction industry Master Plan, 'Road Map' 2003-2010 and IBS 'Road Map' 2011-2015 with achievement is still in progress and which is still an initial stage [2].

This relationship has often been the subject of various scholars and writers, among whom are Maryam et.al [5]; Nawi et.al [4] and Abdullah et.al [11]. It has been stated in the CIDB Survey [12] that $15 \%$ of the Malaysian construction project employ the IBS method while the mid-study of IBS 2007 establishes that only $10 \%$ had been completed using the IBS in 2006, as compared to the target of use of 50\% IBS in 2006 and 70\% approaching 2008 as its target [13]. Meanwhile it is found that less than 35\% from the total number of projects in Malaysia has used at least one IBS product in 2006.

What are given below are some matters regarding the existing IBS issues and policies, but one fact remains that one particular rule or one specific and detailed Act is yet to be laid out.

IBS 'Roadmap' 2003 to 2010 was endorsed by the Cabinet of Malaysia on $29^{\text {th }}$ October 2003. One of the aim of this Roadmap is to reduce the dependency on foreign labour in the national construction industry also enhance the quality, productivity, safety and competition in the construction industry. Other than generating new economic growth towards the IBS component industry through open construction system [13], the government has made an effort to allocate various incentives in the yearly budget of 2005 and 2006. In the 2005 budget, the Government has granted full exemption to the CIDB levy for housing projects which adopt more than $50 \%$ content of IBS. Meanwhile in the 2006 budget, it is stated that the capital expenditure on the purchasing of moulds for IBS component manufacturers is expedited, via Expedited Capital Allowance to be claimed in the period of three years. These efforts are able to mitigate the costs of construction components, like the beam, column, walls and floors (CIDB).

According to Azman et.al [15][16] the government has given the mandate to industry player which is the fact that $70 \%$ of the IBS component should be used in government projects with the Treasury value of RM10 million (2008), To look at this order, writer refers to the Treasury's circular dated $31^{\text {st }}$ October 2008. It is directed to all ministries, heads of the department, state governments, statutory bodies and local authorities. Among the things that have been brought up are the use of the open system through the coordination modular MS 1064, the requirement of $70 \%$ IBS component content must be used in government projects, the National IBS Secretariat as the coordinator, the Implementation Coordination Unit, the Prime Minister's office as the monitoring party and the CIDB IBS Center as the local reference center, CIDB (2008). In the period of implementation of the latest IBS namely the IBS 'Roadmap 2011-2015', the government sector will maintain its enforcement of 
the IBS component use as much as $70 \%$ for projects worth RM million, as outlined in the circular Item 7./2008 [17].

The government has improved $1^{\text {st }}$ edition of IBS Road Map 2003-2010 to 'Roadmap 2011-2015'. The Construction Industry Master Plan (CIMP 2006-2015) was gazetted in December 2006 and serves as the industry's direction. The direction of the IBS 2011-2015 in replacement of the current directional plan was issued in the last months of 2010. The objective is to achieve high level performance as the outcome of the IBS implementation. The new action plan will focus on the private sector to adopt IBS. To stay focus, the concentration is on three basic policies; quality, efficacy and sustainability. A sustainable IBS industry will contribute to a competitive construction industry. Therefore, 37 steps of action have been proposed to be achieved by the year 2015. It is anticipated that the plan will be able to play a part in realizing a more sustainable IBS in both public and private sectors. The aims for the plan aforementioned are listed as follows:

1. To retain the existing momentum, $70 \%$ of the IBS content are allocated for the public sectors' construction projects until 2015.

2. To increase the existing content of the IBS to $50 \%$ for the building projects of the private sector by the year 2015 .

Harmonious with the technologically modern development, the latest and the most effective approach of the construction technology is crucial. To date, the IBS is a method that is gaining popularity due to its strengths and benefits [18]. IBS uses an innovative and clean moulding technology (namely steel, aluminium and plastics). IBS offers the benefit in ascertaining the cost and time, achieving better quality and productivity of construction, mitigating risks related to occupational safety and health, combating the issue of skilled workers and the dependency on foreign labour manually and achieving the main aim of reducing the overall costs of construction [18].

\section{The advantages of the industrialised building system.}

The practical benefits of the IBS have been confirmed by researchers such as Nawi [19], Tam [20], Badir [8] and Hassim [21].

a) Optimising the use of materials, repeating and reusing the molds, at the same time reducing the remnants of the materials. Factories are able to produce quality products from rational and efficient manufacturing processes, skilled workers, repetitious procedures and quality and controlled supervision [18].

b) Shorter duration of construction - which is less than half of the in-situ cast construction method [20].

c) The construction operations are not impacted by the bad weather as readily installed components are made in the factory and later sent to the construction site [8].

d) The manufacturing work is done in the factory in a centralised manner, altogether reducing the number of workers on the site, high degree of mechanisms is involved [19].

e) Opening more opportunities for the architecture to be more innovative when this system creates opportunities to designers and contractors to explore more into creative designs using the IBS approach [17].

f) Environmentally-friendly construction method and materials will lower the hazardous effects to the environment and minimise the production of construction wastes [20].

g) Advantage in terms of reducing the number of unskilled workers [17].

h) The reduced intake of foreign workers in the construction sector (for Malaysian cases), which is previously plagued with the influx of foreign workers [17].

i) Reducing the overall construction, material and labour costs effectively, through the practice of the grand-scale production of building components [8].

j) Better supervision and monitoring at the expense of enhancing the quality of the readilyinstalled products [17].

k) Promoting more planned, and safer, construction site surroundings [20].

1) Elevating the image, the integrity of the building designs and the construction [19]. 


\section{Supply Chain Flexibility}

According to Soroor and Tarokh [1] the term 'supply chain' is defined as : " the integration of key business process from end user through original suppliers that provides products, services and information that add value for customers and stakeholders".

Tommelein [2] explains that "the chain of supply management implies the practice of groups of companies and individuals who are working collectively in the related network of process structure to gain the end-user satisfaction during the benefit-sharing among all involved in the chain".

Supply chain integrates the flow of integrated processes of physical materials, information and cash flow along the chain value from the manufacturers, suppliers and a broad-range distribution network and customer logistics. Business competition has become very strong in the global market in the 1990s and 2000 [3]. The supply chain management practice is created to deliver the products to the right place, at the right time, in the right quantity, with the right quality to customers at the lowest cost $[4,5,6]$.

Gilmore [22] explained that the chain supply denotes the ability to provide a quicker response to demands and opportunities. Gilmore [22] also classifies flexibility into two types, namely micro flexibility and macro flexibility. Micro flexibility means just how fast the supply chain can detect and respond to issues and opportunities in the short term - and even now. The delay of the truck, demands that have become drastic, customers needing several types of packaging and handling; how fast and how effective can these be done? On the other hand macro flexibility refers to the speed at which the company's supply chain adapts and implements the new strategies and programmed to support the changes in the company's strategies as a whole or the change of the market. For instance, the company decided to create customers' e-commerce through a direct channel. How fast can this be delivered and is this possible?

In an increasingly competitive environment, the market is internationalized with a dynamic range of customers. Customers have their own demands and needs, where their expectation lies in a better quality also faster services and delivery. Business organizations require lower costs, faster reactions to the changing demands, an enhanced supply manufacturing and network for an advantageous competition in the market. The power shift in the supply chain to retailers and the distribution of important roles as manufacturers to obtain products and services to the customers has been observed. The lack of supervision and globalization dictate that businesses are to deal with various supply networks to succeed [4]. With the emergence of business challenges that are related to the enhanced volatility of the environment, products' exponential life cycle, and the organizational internal complex reaction to the changing demands and the intricacies of the global logistics, organisations have provided supply chain as a competitive advantage resource $[7,8,9]$

In the Supply Chain Management (SCM) context, it involves materials' physical flow integration, information in the supply chain to create business value. Supply Chain Council (2008) through SCOR (Operational Supply Chain Reference) also explained the business plan activities, resources, manufacturing, delivering and returning as a framework of measurement of business relationships, metrics, benchmarking processes crossing a more functional relationship.

The theory and concept of the flexibility supply chain model are pioneered by Duclos et. al. [10] and Lumnus et. al. [5]. Then it followed on the production flexibility towards the cross-functional integrated dynamic industry. Duclos et. al. [10]. Then it have produced a node supply chain concept between customers and suppliers. It comprises of supplies, logistics, information system, market, operation, and organisational leniency. Meanwhile, Lumnus et. al. [5] produce an operational system concept, the logistics process, supply chain, organisational design, and information system by creating a significant (supply chain asset) and (such as customers satisfaction, responsive) as insignificant benefits. 


\section{Reviews of Statement Of The Supply Chain Flexibility Problems}

These factors of flexibility serve as an aset of prima facie assumptions based on through literature reviews. This assumption refers to the existing condition and situation of the supply chain that is too rigid and is not flexible in meeting the needs and demands of the IBS development in Malaysia. Such an inflexible condition causes various problems which altogether impede the growth of the IBS although it had been introduced since the year 1964. The following finding in desk study highlighted issues and problems of IBS the Malaysian IBS industry:

a) Studies done by the CIDB in 2003 show the level of use of the IBS in the local construction industry is only $15 \%$ CIDB [13]. The actual reason behind sticking to the conventional construction is due to the IBS intensive capital cost compared to the conventional labour costs. Additionally, the failure of the pre-cast system introduced in Malaysia as there are several western systems that do not seem to be compatible to be used in Malaysia. Also, a flawed installation of site has caused the problem of leakage due to the inexperienced workers installing the IBS component at the early stage [23]. These problems have brought along a bad image and reputation to the IBS. In addition, a lot of contractors have chosen to use of the conventional type of construction due to the cost and over supply of foreign workers in Malaysia. Other than that, local workers are also uninterested to be part of this industry as it does not offer much and due to the low emphasis on their working conditions [17].

b) Nawi [11] stated that current practice of conventional IBS, the chosen contractor will be paid between $10 \%$ and $25 \%$ from the total of contract value as the start-up payment by customer. However, in the IBS project, the contractor is expected to produce early expenditure and most will pay to the supplier before any payment of work is made. Usually, local contractors do not have sufficient funding for this early-stage IBS-based projects [11].

c) Fikri [12] and Nawi [13] point out that IBS suppliers would normally require a deposit of $75 \%$ from the total manufacturing of the IBS component before any of the components are sent to the project site. There is only one way for the contractor to do it which is by applying for a bond from financial institutions as a deposit guarantee with the IBS producer. Unfortunately, for some contractors, especially new ones, they will face a problem to obtain these bonds. Subsequently, this will impact the IBS project development process.

d) Potts [14] states that the lack of, or the delay in supplying the IBS information, equipment and materials to the site serve as the main obstacles to the success of the implementation of the IBS projects.

e) Love (15), Nawi [4,5] and Person [16] point out that the issue of communication, the weakness of integration among designers and construction. But it can be mitigated, with involving the suppliers (as an expert related to design and procurement stage). At the initial stage of the project, the project performance needs to be improved through the mitigation of wastes according to schedule, costs , communication issues and opposite relationships.

f) Simon Report [17], Banwell [18], Latham [19] and Egan [20] state that the information obstacle flow between the separation of the traditional design and the production process that have been criticized since 50 years ago.

g) Love [15] explains the gap in the relationship in the supply chain cycle among the life cycles of various phases that integrate with one another. 
h) MPEN [21] states that most entities of item production and services in Malaysia are segregated, non-interactional and cooperative with one another.

i) Fitri [22] states that issues pertinent to the requirement for manufacturing are identified as something burdensome in the implementation of the IBS in Malaysia.

j) Syukor [2] maintains that the issue of supply management chain system is the integration through the superviser of the procurement system in the IBS itself.

k) Chung [23] and Nawi [13] explain that the construction location is too far from the locations of the manufacturers or suppliers. Most of the IBS producers are located in industrial areas like in the Klang Valley, Seremban, or Butterworth. This situation has indirectly enhanced the cost of the logistics component and transportation in the project funding if it is situated in villages especially in the north and east of Malaysia. Following this, the contractor has to shoulder some extra costs for logistics and transportation to obtain the delivery of components of IBS to the project site. This is identified as one of the main obstacles in the act of receiving the implementation of the IBS components in the Malaysian construction industry, especially in the north area and in the rural areas.

1) Nawi [19] also states that the Malaysian IBS projects are still based on the traditional design form, that leans on the needs of the consumers. The architect will produce design drawings which will be sent to the Structural Engineer. After the design is ready, a detailed specification will be handed to the main contractor for calculation and quotation of price. Then, the document will be given to the main contractor where he will discuss further with the producer and until the end, is held accountable for the building structure. This method is known as "beyond-the-wall syndrome'. This practice only allows both the producer and contractor after the design stage, where it causes a problem in the supply chain such as, the delay in the project, delay in supply and so on.

m) CIDB [24] elaborates that although the level of acceptance and practice of the SCM is credible, the understanding of the SCM is still far ahead and weak in certain aspects. This leaves the government agencies with heavy responsibilities in relation to the construction to enhance the understanding of the construction players on the practice of the SCM.

n) CIDB [24] The pioneer of the industry believes that there will be a new creation of the SCM practice which is ineffective. Issues such as, material scarcity on the site, the delay in supplies of materials in the market, lack of equipment and lack of communication among the players have become somewhat commonplace to the industry. Fundamentally speaking, these issues are related to how the players, the technology and effective process can be handled effectively by the pioneers of the industry starting from the top stage to the lower-level activities.

On the other hand, CIDB [24] infer the following point of issues of the logistics network associated to supply chain of IBS are :

1) Able to respond quickly towards the change of demands

2) Manage properly the warehouse capacity to meet the changing demands.

3) The different adaptability of the demand system as a response to changing demands

4) The smooth running of the delivery services.

5) Bringing in the customers' returns, if necessary.

According to Hamid (24) the disintegration of the construction's supply chain is the main factor for the low construction performance and limited selection on the IBS construction system. According to Ketchen [25] traditional supply chain often concentrates on one main outcome like speed or costs, while the best value of the supply chain gives priority to the speed or cost, quality and flexibility. 


\section{Conclusion}

The flexibility of the supply chain management is indeed giving a great impact to the development and progress of the national construction industry particularly the Industrialised Building System. The issue of inflexibility in the supply chain management occurred since more than 49 years ago is believed to be one of the main reasons for the CIDB's failure in reaching the target as contained in the Master plan (CIMP) 2003-2010. Through literature reviews it was suggested that explored to justify the reason and necessary steps of action. This study aims to identify and analyse the factor of the IBS supply chain flexibility as a success factor's of the IBS supply chain flexibility.

\section{References}

1. Kok, C. (2012). ETP projects to power Malaysia into new status. Retrieved Saturday August 25 2012

2. Abd Syukor, A. S., Mohammad, M.F., Mahbub, R. and Ismail, F. (2011). Supply Chain Integration in Industrialised Building System in the Malaysian Construction Industry. The Built \& Human Environment Review, 4(Special Issue ), 108-121.

3. Akmal Aini Othman, S. A. R. (2010). Supply Chain Management In Building Construction Industry : Linking Procurement Process Coordination, Market Orientation And Performance. Journal of Surveying, Construction \& Property Vol. 1( Issue 1), 23-46.

4. Nawi, m. n. M., Lee,A., Arif,M. (2010). The Barriers In The Malaysian Construction Industry : AStudy In Construction Supply Chain Perspective.

5. Nawi, M. N. M. L., A. Arif,M. (2010). The IBS Barries in the Malaysian Construction Industry : A study in Construction Supply Chain Perspective. Papers And PostGraduate Papers From The Special Track Held At CIB World Building Congress 77-92.

6. Maryam Qays, K. N. M., H.M.A. Al-Mattarneh. (2010). Industrialized Building System in Malaysia : Challanges and the Way Forward. ArchiCivi.com, 1-14.

7. Warszawki, A. (1999). Industrialized and Automated Building Systems. London:E \& FN Spon.

8. Badir, Y. F., Kadir, M.R.A and Hashim, A.H.,. (2002). Industrialised Building Systems Construction In Malaysia. Journal of Architectural Engineering, 8(1).

9. Hong, O. C. (2006). Analysis of IBS for school complex. Universiti Teknologi Malaysia (UTM).

10. Thanoon, W. A. M., Peng, L.W., Abdul Kadir, M.R., Jaafar, M.S. and Salit, M.S. (2003). The Experiences of Malaysia and Other Countries in Industrialised Building System in Malaysia. Paper presented at the Proceeding on IBS Seminar., UPM, Malaysia.

11. Kamar, K. A. M. (2011). Kajian Mengenai Kontraktor IBS yang Berdaftar dengan CIDB Penyataan Masalah Retrieved 19 Okt 2011, 2011, from http://ibsresearch.blogspot.com/

12. Abdullah, M. R. A. E., C. (2010). Selection criteria framework for choosing industrialized building systems for housing projects. Procs 26th Annual ARCOM Conference, 1131-1139.

13. CIDB. (2003). IBS Roadmap 2003-2010. Kuala Lumpur.

14. Zuhairi Abd. Hamid, K. A. M. K., Mustafa Alshawi,Maria Zura Mohd Zain,Mohd Khairolden Ghani,Ahmad Hazim Abdul Rahim. (2011). Industrialised Building System (IBS) Construction Supply-Chain Strategies of Malaysian Contractors. Sixth International Conference on Construction in the 21st Century (CITC-VI)“Construction Challenges in the New Decade".

15. M.N.A. Azman, M. S. S. A., T.A. Majid, M.H. Hanafi. (2010). The Common Approach in OffSite Construction Industry. Australian Journal of Basic and Applied Sciences, 4(9): 4478-4482. 
16. M.N.A. Azman, M. S. S. A., T.A. Majid, M.H. Hanafi. (Dec 2010). Perspective of Malaysian Industrialized Building System On The Modern Method Of Construction. APIEMS, The 11th Asia Pasific Industrial Engineering And Management System Conference, 1-7.

17. Malaysia, C. I. D. B. C. (2007). Construction Industry Master Plan (CIMP 2006-2015) Summery Exclusive: Construction Industry Development Board (CIDB) Malaysia

18. Kamarul Anuar Mohamad Kamar, Z. A. H. Z. I. (2010). Modernising The Malaysian Construction Industry Through The Adoption Of Industrialised Building System (Ibs). The Sixth International Conference On Multi-National Joint Ventures For Construction Works Kyoto, Japan.

19. Nawi, M. N. M., 1 Lee, A.,2 and Nor, K. M.3. (2011). Barriers to Implementation of the Industrialised Building System (IBS) in Malaysia. The Built \& Human Environment Review, Volume 4, 22-35.

20. Tam, V. W. Y., C.M. Tam, S.X. Zeng, W.C.Y. Ng. (2007). Towards Adoption of Prefabrication in Construction. Build.Environment, 42, 3642-3654.

21. Hassim, S., M.S. Jaafar, S.A.A.H Sazali. (2009). The Contractor Perception Towers Industrialized Building System Risk In Construction Project In Malaysia. Am. J. Applied Sci.,, 6, 937-942.

22. Gilmore, D. (2010). Supply Chain Digest. What is Supply Chain Flexibility

23. CIDB. (2005). IBS Digest. Construction Industry Development Board

24. CIDB. (2011). Supply Chain Management In The Malaysian Construction Industry (Cream/0801-07-ST1-SA2-04): Construction Research Institute of Malaysia.

25. David J. Ketchen Jr.a, G. T. M. H. b. (2007). Bridging organization theory and supply chain management: The case of best value supply chains Journal of Operations Management (Science Direct Elsevier), 25, 573-580 